\title{
SUSTAINABILITY OF SCHOOLS: A MULTIDISCIPLINARY APPROACH TO STUDYING AIR QUALITY IN EDUCATIONAL BUILDINGS
}

\author{
CHIARA TONELLI ${ }^{1}$, LUCIA FONTANA ${ }^{1}$, ILARIA MONTELLA ${ }^{1}$, GINEVRA SALERNO $^{1}$, \\ VALERIA VITALE ${ }^{1}$, LIVIA LEONI ${ }^{2}$, GIORDANO RAMPIONI ${ }^{2}$, ANTONELLA SGURA $^{2}$, \\ MARCO TESCARI ${ }^{2}$, ION UDROIU ${ }^{2}$, ELISABETTA MATTEI ${ }^{3}$, ELENA PETTINELLI $^{3}$, \\ ILARIA AMORI ${ }^{4}$, EMILIA PABA $^{4} \&$ ANTONELLA MANSI $^{4}$ \\ ${ }^{1}$ Department of Architecture, Roma TRE University, Italy \\ ${ }^{2}$ Department of Science, Roma TRE University, Italy \\ ${ }^{3}$ Department of Mathematics and Physics, Roma TRE University, Italy \\ ${ }^{4}$ DiMEILA, INAIL, Italy
}

\begin{abstract}
This work reports the preliminary results of the "Sustainability of Schools" (SoS) project, a multidisciplinary project funded by Roma TRE University which involves the departments of architecture, engineering, economics, mathematics and physics, and sciences at Roma Tre University and the Department of Occupational and Environmental Medicine Epidemiology and Hygiene of Italian Workers' Compensation Authority (INAIL). Healthy indoor air and thermal comfort are important for any type of building, but they play an essential role in teaching and learning processes because the intellectual activities are intimately conditioned by these. There is a significant bibliography on the indoor environment in office buildings, while few studies have been focused on educational buildings. The main objective of this project is to form a research team with specific areas of expertise in different fields aimed at defining technologies, methodologies, and protocols to assess the use for health, wellbeing, and energy saving in educational buildings. In this preliminary report of activity, two types of construction have been chosen as case studies, representative of a large number of Italian schools. A building of the first kind, prefabricated and built during the 1960s, is located on the Rome seaside. Two buildings of the second kind are historical properties of Roma Tre University in Rome downtown and are representative of a large number of masonry buildings with thermal mass. Here we present a multidisciplinary methodological approach for measuring indoor air quality parameters (i.e. temperature, relative humidity, concentration of pollutants, presence of ionizing radiation, biotic and abiotic factors) and the development of a class of numerical models. Overall, we paved the way for the future development of more advanced models integrating measures and models.

Keywords: indoor air quality, air pollution modelling, aerosols and particles, emission studies, health effects, monitoring and measuring, educational buildings, thermal comfort, computer fluid dynamics, biogenic emissions, airborne microorganisms.
\end{abstract}

\section{INTRODUCTION}

The COVID-19 pandemic has highlighted people's awareness of the importance of air healthiness much more than before this global emergency, and Indoor Air Quality (IAQ), especially as it relates to the health and comfort of building occupants, is the main topic of this ongoing research.

It has been estimated that European people spend about $90 \%$ of their time in both public and private indoor environments, such as homes, workplaces, schools, transportation vehicles, gyms [1].

So, the IAQ has a great impact on health and quality of life. For many people, the health risks from exposure to indoor air pollution may be greater than those related to outdoor pollution. 
Indoor environments are usually a mix of outdoor pollutants (caused by industrial activities, vehicular traffic, heating, gas emissions), which can enter by infiltrations through natural or mechanical ventilation systems, and indoor contaminants (emissions from building and furnishings materials, burning fuels, heating and cooling systems emissions, products for housekeeping, etc.).

Health effects from indoor air pollutants may be experienced soon after exposure or, possibly, years later. For this reason, in the last few decades, IAQ has received increasing attention from the international scientific community in order to improve comfort, health, and wellbeing levels of building occupants.

IAQ is one of the many factors that go into the definition of Sick Building Syndrome, with its microbiological and chemical exposure risks, not adequately characterized by current assessment approaches. In addition, the thermophysical aspects of indoor air, i.e. temperature, humidity and velocity, related to the heating, ventilation and air conditioning systems used in buildings, on the one hand are in a cause/effect relationship with the indoor polluting sources, and on the other hand they contribute to determine other aspects of psychophysical stress (thermal discomfort) to the occupants [2], [3].

One way to check indoor air quality is to take advantage of good natural ventilation in buildings. In indoor spaces occupied by people, $\mathrm{CO}_{2}$ concentration is often used as a surrogate indicator of the adequacy of air ventilation relative to occupant density and metabolic activity. To eliminate most health complaints and discomfort feeling, indoor $\mathrm{CO}_{2}$ should be less than approximately $600 \mathrm{ppm}$ above the outdoor levels.

However, restrictive European regulations [4] on energy savings have caused severe limitations of natural air leakage for occupied buildings, and the reduced ventilation in many naturally ventilated buildings has caused a higher concentration of pollution and poor indoor air quality. As a consequence, ventilation measurements are of great importance for estimating the indoor air exchange rate and for evaluating IAQ [5].

Healthy indoor air and thermal comfort are important for any type of building environment, but they play an essential role in teaching and learning processes because the intellectual activities, such as understanding of concepts, abilities of problem solving, and attitudes towards learning, are intimately conditioned by these.

There is a significant bibliography on the indoor environment in office buildings, while few studies have been done on educational buildings. Considering that educational buildings often have much higher occupancy density than office buildings, the estimation of their indoor air condition is becoming a new trend. Poor IAQ has not only a negative impact on students' health but may indirectly affect their learning performance [6], [7].

In relation to the possibility of modelling this complexity, over the last years, many studies have underlined a growing interest towards indoor climatic control and the energy efficiency of educational buildings. To date, the use of Computational Fluid Dynamics (CFD) numerical models represents a good way to go for studying these strategies, as confirmed by a growing literature [8], [9].

Thanks to the overcoming of some limits and simplification of the multi-zone models [10]-[12], currently the most commonly used to estimate the building energy consumptions, CFD models can provide more detailed estimation of fluid flow motions and fields of temperature, velocity, relative humidity, pollutant concentration, etc.

The spatial distribution of these parameters is crucial to comfort condition prediction, especially when natural ventilation strategies are used. In Mediterranean regions, natural ventilation strategies present, in summer, a viable alternative to mechanical ventilation systems. 
Through CFD models it is possible to control $\mathrm{CO}_{2}$ concentration, temperature and humidity levels and special distribution using natural ventilation to maintain comfort conditions [13].

Moreover, especially when the buildings have a high thermal mass - as often occurs in historical Italian buildings - CFD models are helpful to provide a detailed estimation of thermal storage in building masses and passive cooling effects on adaptive thermal comfort [14].

Recent studies used CFD as an approach to explore the indoor air pollution in enclosed spaces, including schools, classrooms and study halls, often coupling modelling to experimental measurements.

Common indoor air pollutants in educational buildings are volatile organic compounds (VOCs). Bourdin et al. investigated formaldehyde emission behaviour of building materials using onsite measurements of air phase concentration at material surface as input data of CFD model to estimate the indoor air pollution of a newly built classroom [15].

High occupant densities result in significant heat gains and carbon dioxide emission for building occupants. For this reason, in educational spaces it is often necessary to have a significant use of air conditioning and high levels of air change rate.

Noh et al. set an experimentally validated CFD model of a lecture room, in order to estimate the $\mathrm{CO}_{2}$ reduction in the occupied zone due to the discharge airflow rate of a ceiling type air-conditioner and the mechanical ventilation rate [16]. Salma et al. underlined that aerosol particles in a classroom show large variability in time and space, due the different sources and properties of the indoor microenvironments, suggesting to perform CFD studies in various closed spaces to acquire a statistically significant knowledge to identify both common tendencies and specific features of the indoor pollutants [17]. Wang et al. set a CFD model on a recent-built school building, in order to assess indoor condition and $\mathrm{CO}_{2}$ concentration with different scenarios: natural ventilation [18], heat recovery with displacement ventilation [19], [20], and heat recovery with passive night ventilation precooling [21].

Furthermore, thanks to the detailed descriptions of the flow-field variables, CFD is a consolidated approach to assess natural ventilation performance, including different ventilation strategies comparison [9], [22], [23].

\section{RATIONALE AND AIMS}

This work reports the preliminary results of the "Sustainability of Schools" (SoS) project, an interdisciplinary project funded by Roma TRE University, which involves the Departments of Architecture, Engineering, Economics, Mathematics and Physics, and Sciences of Roma Tre University and the Department of Occupational and Environmental Medicine Epidemiology and Hygiene of Italian Workers' Compensation Authority (INAIL).

The general objective of this project is to form a research team with specific areas of expertise in different fields aimed at defining technologies, methodologies and protocols to assess the use for health, well-being and energy saving in educational buildings.

The specific objectives of the work here presented have been aimed to define and share methods and expertise among SoS researchers, in order to select optimal multidisciplinary teams on the basis of buildings characteristics, for future integrated analyses and CFD models development.

In this preliminary report of activity, two types of constructions have been chosen as case studies, representative of a large number of Italian schools. A school from the 1960s, built with prefabricated panels, belongs to the first type of constructions and is located on the Roma's seaside. Two buildings, belonging to the second type, are historical properties of 
Roma Tre University in Roma downtown, and are representative of a large number of masonry buildings with thermal mass.

The two types of construction were selected with reference to different construction materials and technologies, and consequent different thermophysical properties. Of course, these features affect heat exchanges, indoor thermal comfort and air quality.

The first type of buildings, for its constructive and usage characteristics, is interesting to monitor $\mathrm{CO}_{2}$ levels and biological sources of indoor pollutants. As a matter of fact, the schools are complex workplaces, considering the peculiar and diversified activities carried out in. Inadequate changes of air and crowding are critical factors for the concentration of pollutants of various kind, including those of biological sources. In fact, poor building maintenance and hygiene can facilitate the accumulation and proliferation of biological agents potentially harmful to the health of the occupants. The interest in the air quality in the schools arises from the fact that indoor bacteria and fungi exposure may have adverse health effects. Inhalation of fungal spores may cause upper respiratory (nose and throat) tract symptoms, cough, wheeze and asthma symptoms in sensitized children [24]. In addition, it is important to measure $\mathrm{CO}_{2}$ in this peculiar kind of crowded environments because high $\mathrm{CO}_{2}$ levels, correlated to sickness, negatively affect attention and learning processes.

The two buildings representative of the second type were selected for the following reasons. The first one, built in radon-rich tuff rock, allow to monitor radon emissions and set up a method for genotoxic damage analysis. The second building is characterized by high thermal mass; hence it has been used as example for tuning and validating a CFD model aimed at assessing the efficiency of nocturnal natural ventilation protocols.

Here below, the preliminary results obtained by each partner of the SoS cluster are collected and discussed with respect to the SoS aims.

\section{METHODOLOGICAL APPROACH, RESULTS AND DISCUSSION}

\subsection{The 1960s school: $\mathrm{CO}_{2}$ measurement survey}

Several studies, including experimental campaigns, with in situ measurements of the IAQ and thermo-hygrometric variables, have had the aim of characterizing school environments with regard to air quality and comfort [25], [26]; the most suitable methods and ventilation systems to ensure air quality in school environments, and their impact in particular on $\mathrm{CO}_{2}$ concentration [27]-[30].

With reference to ventilation in schools, the European SINPHONIE guidelines [31] recommend to introduce the ventilation, natural or mechanical, of the classrooms, and suggest, among other things, that classrooms should be equipped with $\mathrm{CO}_{2}$ monitors to report high levels of this parameter (over $700 \mathrm{ppm}$ ), in order to immediately activate ventilation when the threshold is exceeded.

This suggested value is even more severe than that indicated by the UNI EN 16798-3: 2018, which specifies, as limit values for indoor environments (Cat. I, the presence of children or elderly people) $550 \mathrm{ppm}$ as an indoor-outdoor $\mathrm{CO}_{2}$ concentration differential, and $1000 \mathrm{ppm}$ as a limit for $\mathrm{CO}_{2}$ concentration (for $450 \mathrm{ppm}$ external environment concentration).

In the school, selected as the first case study, a preliminary survey was conducted to assess the $\mathrm{CO}_{2}$ concentration in the classrooms, as well as other thermo-hygrometric parameters relevant for comfort (air temperature, air velocity, relative humidity). $\mathrm{CO}_{2}$ has been measured through a Testo 160 IAQ (Measuring range $0-5,000 \mathrm{ppm}$, Accuracy $\pm(50 \mathrm{ppm}+2 \%$ of v.m.) at $+25^{\circ} \mathrm{C}$, Resolution $\left.1 \mathrm{ppm}\right)$. 
Fig. 1 shows results referred to a 24 pupils' classroom, and $\mathrm{CO}_{2}$ has been monitored for two weeks from 25/03/2019. Results showed a $\mathrm{CO}_{2}$ concentration with average value equal to $660 \mathrm{ppm}$. Checking the survey during school hours $(8-14)$, the value becomes much higher, varying from about 1000 to $2500 \mathrm{ppm}$, with peaks of over $3000 \mathrm{ppm} . \mathrm{CO}_{2}$ concentration grows during the morning due to the human presence and to absence of air exchange. During school closing days the concentration remains constant around the minimum values, similar to the weekday night period. The presence of the operating heating system dominates the air temperature trend. Sometimes there is a slight oscillation in the value of the $\mathrm{CO}_{2}$ concentration in the morning, probably due to the windows opening during half-morning break.

These results confirm the importance of indoor ventilation, especially in the classrooms, continuously occupied during many hours.

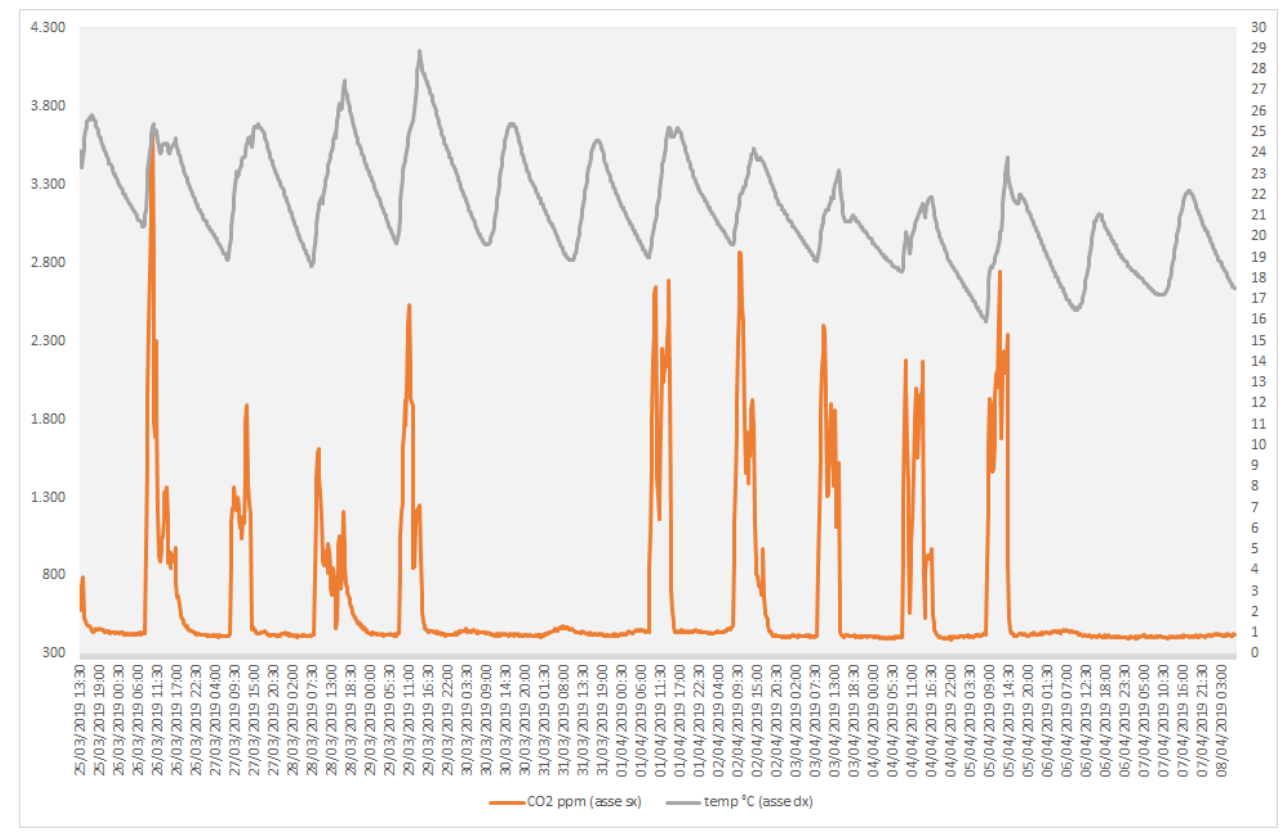

Figure 1: $\mathrm{CO}_{2}$ concentration and air temperature values in the investigated classroom.

\subsection{The 1960s school: biological sources for indoor pollutants}

This study reports the preliminary results of an investigation aimed at evaluating the hygienic conditions in the classrooms of a school building by the detection of airborne bacterial and fungal concentrations and the evaluation of microbial contaminants on the environmental surfaces.

The investigation was carried out in the school building located in Ostia. Air samples from six classrooms were collected between April and May 2019 during the normal scholastic activities.

Air samples were collected in the middle of the monitored room using an orthogonal impact sampler (Surface Air System, SAS) and, at the same time, air samples were taken outside the building. 
After the sampling, Trypticase Soy Agar (TSA) plates were incubated at $37^{\circ} \mathrm{C}$ (for mesophilic bacteria growth) and at $22^{\circ} \mathrm{C}$ (psychrophilic bacteria growth) for 48 hours. For the fungal growth, Malt Extract Agar (MEA) plates were incubated at $25^{\circ} \mathrm{C}$ for $5-10$ days. Bacterial and fungal counts were expressed as $\mathrm{CFU} / \mathrm{m}^{3}$ (CFU, colony forming units).

Air microbiological quality was evaluated using the following microbiological contamination indices [24], [32]: $\mathrm{GIMC} / \mathrm{m}^{3}$, the global index of microbial contamination, given by the sum of the total airborne microorganisms (bacteria and fungi); IMC, index of mesophilic contamination, given by the ratio between $\mathrm{CFU} / \mathrm{m}^{3}$ measured for mesophilic and psychrophilic bacteria at the same sampling point; AI, amplification index, given by the ratio between the GIMC $/ \mathrm{m}^{3}$ values measured inside and outside the building.

The evaluation of microbial contamination on the surfaces of school desks was performed using RODAC plates containing TSA, incubated at temperatures ranging from $22^{\circ} \mathrm{C}$ to $37^{\circ} \mathrm{C}$ and for different times depending on the target microorganism. Results were expressed as the number of colony-forming units per unit of surface $\left(\mathrm{CFU} / \mathrm{cm}^{2}\right)$. Indoor and outdoor temperature and relative humidity were monitored by a TH-CALC TM thermo hygrometer during the collection of the samples. Descriptive statistical analysis was performed to provide mean, geometrical mean and range of $\mathrm{CFU} / \mathrm{cm}^{2}$.

The school building was constructed in 1964 . The classrooms varied in size with a mean of $75 \mathrm{~m}^{3}$ and none of these had a mechanical air ventilation system.

The mean indoor temperature and relative humidity values were $21.2^{\circ} \mathrm{C}$ and $62 \%$, while the outdoor ones were $18.2^{\circ} \mathrm{C}$ and $64.3 \%$, respectively.

The indoor airborne bacterial and fungal concentrations had mean values of $33 \mathrm{CFU} / \mathrm{m}^{3}$ (range 2.5-88), $686 \mathrm{CFU} / \mathrm{m}^{3}$ (range 378-1254) and $1624 \mathrm{CFU} / \mathrm{m}^{3}$ (range 666-3232) for fungi, psychrophilic and mesophilic bacteria, respectively.

Average microbial concentrations outside the school building were $38 \mathrm{CFU} / \mathrm{m}^{3}$ (range 0-60 CFU $/ \mathrm{m}^{3}$ ), $18 \mathrm{CFU} / \mathrm{m}^{3}$ (range $0-24 \mathrm{CFU} / \mathrm{m}^{3}$ ) and $26 \mathrm{CFU} / \mathrm{m}^{3}$ (range $12-40 \mathrm{CFU} / \mathrm{m}^{3}$ ) for fungi, psychrophilic and mesophilic bacteria, respectively. In the classrooms, mesophilic bacteria had higher mean values compared to the other microorganisms. As expected, bacterial concentration resulted very low in the outdoor air. GIMC/m ${ }^{3}$ was $2427 \mathrm{CFU} / \mathrm{m}^{3}$ (range 1090-4124 $\mathrm{CFU} / \mathrm{m}^{3}$ ), confirming the presence of high values of biological contaminants in the classrooms. IMC was 2.4 (range 1-4.5), suggesting a marked anthropogenic contribution to the indoor microbial contamination due to overcrowding or inadequate air change. In addition, also the AI of 17.8 (range 8-30.3) is indicative of the presence of high levels of airborne microbiological contaminants in the indoor environment, as reported in other studies [32], [33]. Lastly, the microbial contamination mean value on the class desks was $2.49 \mathrm{CFU} / \mathrm{cm}^{2}$ but, in some cases, we found values higher than these. As the environmental surfaces can play an important role in the transmission of microorganisms potentially infectious, these results point to the need to pay more attention to environmental surface cleaning.

\subsection{The tuff rock XIX century building: radon and its genotoxic consequences on human beings}

Indoor radon has been recognised as one of the most dangerous gases for human health. Radon is a naturally occurring radioactive gas produced by the radioactive decay of uranium, which can be found in many rocks and soils. Radon can easily escape from these materials into the air decaying and producing further radioactive particles. During breathing processes, the particles are deposited on human cells damaging DNA and potentially causing lung cancer. Indoor radon levels in buildings such as homes, schools, and offices, ranges from 
$10 \mathrm{~Bq} / \mathrm{m}^{3}$ to more than $10,000 \mathrm{~Bq} / \mathrm{m}^{3}$, according to data reported by the World Health Organization (WHO).

Several factors can affect indoor radon concentration: the environment (e.g., outdoor air and natural gases, atmospheric pressure, rainfall, humidity, temperature, ventilation), earthbase building materials, domestic water, etc. Among them, soil and building materials represent the main factor responsible for indoor radon concentration, as commonly used earth-based materials like tuff contain radon in different quantities.

We measured radon concentration in the historical building selected as case study. We used Corentium Plus Airthings with a measurement range between 0 to $50,000 \mathrm{~Bq} / \mathrm{m}^{3}$ and a sampling rate of 1 hour. The instrument has been positioned in the ground floor of the building, close to the entrance of the library, from 24th July 2019 to 20th September 2019.

Fig. 2 shows the measured radon concentration as a function of time in the entire period of study.

The plot shows that the concentration reaches very high values in the time interval indicated by the red double pointed arrow: this period coincides with the summer break when the building remained closed for a long-time preventing ventilation and air exchange in the monitored rooms. Also, the average radon concentration computed in the entire period of study is high (about $486 \mathrm{~Bq} / \mathrm{m}^{3}$ ). However, if we limited our analysis during the opening period of the institute and the working hours, the average radon level decreases significantly to $96 \mathrm{~Bq} / \mathrm{m}^{3}$.

In order to test a possible genotoxic effect (genomic damage), due the radon exposition, a cytogenetic test was used: the micronucleus (MN) assay.

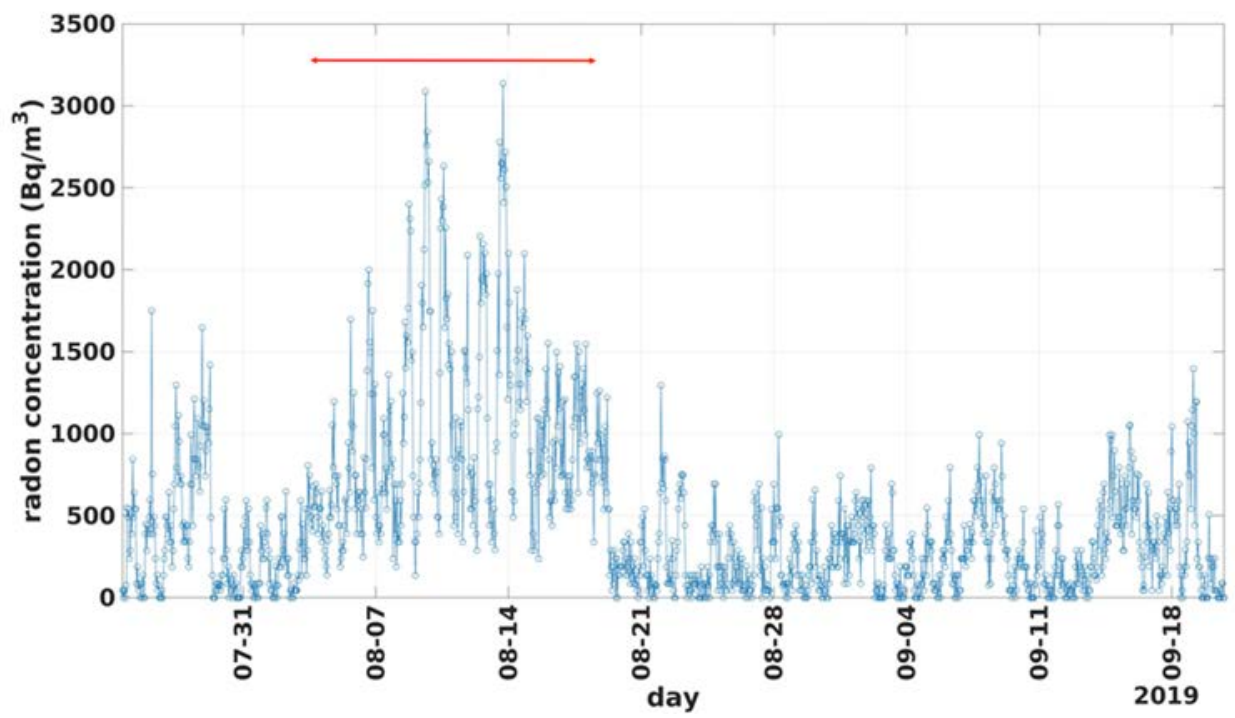

Figure 2: Radon concentration in the historical building case study from 24th July 2019 to 20th September 2019. Red arrow indicates the summer break when the building was closed to the public. 


\subsubsection{Micronucleus test}

For the MN test, two age-matched groups will be compared: one consisting of personnel exposed to Radon and one comprising non-exposed people.

Biological sampling is accompanied by collection of anamnestic data by oral questioning. Presence of chronic and infectious diseases, smoking, drinking, assumption of drugs is taken into account, as well as information on environment, pollution and traffic pollution in the area of residence.

Samples of buccal epithelium are smeared onto glass slides, then fixed in absolute methanol. After being air-dried, the smears are stained with 4',6-diamidino-2-phenylindole (DAPI). Five hundred cells are scored at $1000 \times$ magnification using a fluorescence microscope.

In order to focus our research only on radon effect, firstly our aim was to discriminate possible other factors responsible for damage induction, such as the influence of age, as previously observed [34]. In our preliminary studies conducted so far, we noted higher frequencies of micronuclei in workers compared to students, confirming the influence of age.

Being the results of DNA double strand breaks [35], micronuclei are indicative of genotoxic damage. Indeed, the micronucleus test is one of the most used biomarkers to assess exposure to genotoxic agents [34], including ionizing radiations [36]. Its application on samples taken from buccal epithelium is an easy and non-invasive technique that makes it feasible on groups of potentially exposed people. Moreover, as radon enters the human body via inhalation, the buccal epithelium is one of the first tissues to be exposed to this radioactive element. Although few studies have been conducted so far [37], [38], the micronucleus test on buccal epithelial cells of radon-exposed people seems promising biomarkers to assess exposure and biological effects.

\subsection{The high thermal mass XIX century building: the CFD model}

CFD models simulate the airflow inside the room, solving by numerical integration the Reynolds Averaged Navier-Stokes equations, under the assumption of Newtonian fluid and incompressible flow, generally coupled with a standard k- $\varepsilon$ model to take into account turbulence; temperature is estimate by solving the energy equation.

Some authors implemented few additional scalar equations to solve transport phenomena in air of the following quantities: moisture (expressed as relative humidity $-\mathrm{RH}$ ), carbon dioxide $\left(\mathrm{CO}_{2}\right)$ and particulate concentration (such as pollutant, bacteria, aerosol, viruses, etc.), adopting an Euler-Euler scheme to simulate transport and diffusion in the air.

The system of partial differential equations used in CFD models can assumed the following generic formulation:

$$
\frac{\partial(\rho \phi)}{\partial t}+\nabla \cdot(\rho \phi \mathbf{U})=\nabla \cdot(\Gamma \nabla \phi)+\Lambda
$$

where $\rho$ is the fluid density and $\mathbf{U}=(\mathrm{u}, \mathrm{v}, \mathrm{w})$ is the velocity vector. The unknown physical quantity $\phi$, the diffusive coefficient $\Gamma$ and the source term $\Lambda$, which appear in eqn (1), assume different meanings and analytical expressions, depending on the specific physics they refer to. They are shown in Table 1 and the precise meaning of each symbol is explained in reference [39], [40].

The analytical formulation of the different terms appearing in eqn (1), depending on the specific physics referring to, are shown in Table 1. 
Table 1: Analytical formulation of terms appearing in eqn (1), depending on the specific physics referring to.

\begin{tabular}{|c|c|c|c|}
\hline Equation & $\phi$ & $\Gamma$ & $\Lambda$ \\
\hline Continuity & 1 & 0 & 0 \\
\hline Momentum & $\mathbf{U}$ & $\mu+\mu_{T}$ & $-\nabla p+\mathbf{F}$ \\
\hline $\begin{array}{l}\text { Turbulent kinetic } \\
\text { energy }\end{array}$ & $k$ & $\mu+\mu_{T} / \sigma_{k}$ & $\frac{1}{2} \mu_{T}\left[\nabla \mathbf{U}+(\nabla \mathbf{U})^{\mathrm{T}}\right]^{2}-\rho \varepsilon$ \\
\hline $\begin{array}{l}\text { Dissipation rate of } \\
\text { kinetic energy }\end{array}$ & $\varepsilon$ & $\mu+\mu_{T} / \sigma_{\varepsilon}$ & $\frac{1}{2} C_{\varepsilon 1} \frac{\varepsilon}{k} \mu_{T}\left[\nabla \mathbf{U}+(\nabla \mathbf{U})^{\mathrm{T}}\right]^{2}-\rho C_{\varepsilon 1} \frac{\varepsilon^{2}}{k}$ \\
\hline Energy & $T$ & $\lambda / C_{p}$ & $Q_{s} / C_{\mathrm{p}}$ \\
\hline Relative humidity & $R H$ & $\frac{\delta_{p} \mathrm{p}_{s a t}}{\xi}+D_{w}$ & $Q_{L} / \xi$ \\
\hline Mean age of air & $\tau$ & $\Upsilon$ & $\rho$ \\
\hline $\mathrm{CO}_{2}$ concentration & $\mathrm{CO}_{2}$ & $D_{\mathrm{CO}_{2} / \rho}$ & 0 \\
\hline $\begin{array}{l}\text { Particulate } \\
\text { concentration }\end{array}$ & $\mathrm{C}_{d_{i}}$ & $D+\varepsilon_{\mathrm{p}} / \rho$ & 0 \\
\hline
\end{tabular}

The main goal of the modelling in the SoS project is to apply CFD models on a case study, in order to estimate indoor air quality in relation to natural ventilation and passive cooling effect.

As a first step, we have selected a hall of the late XIX century Academic building case study, and we have defined a measurement campaign to collect data relative to these indoor comfort variables: temperature, velocity, relative humidity and $\mathrm{CO}_{2}$ concentration (the measurement campaign was planned for March 2020, but is currently suspended due to Covid-19 quarantine).

The aim of the experimental campaign is to use the measured values to validate the $3 \mathrm{D}$ model created in CFD software, assessing its effectiveness.

The simulations shown below is a first approach to define a 3D-CFD model of the study hall, carried out with the purpose to determine some basic variable (temperature and velocity), as shown in Fig. 3. 


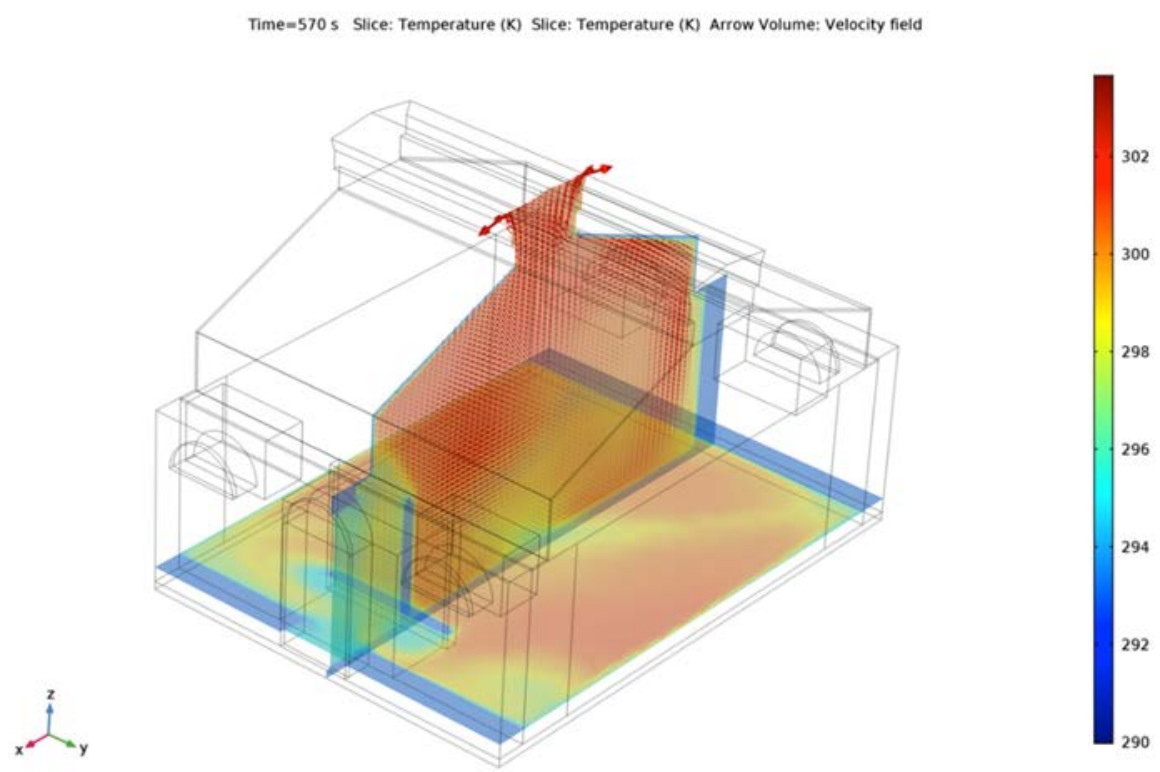

Figure 3: Temperature and velocity field of a 3D-CFD basic model.

The numerical simulations were performed through the Comsol Multiphysics FEM software, release 5.2a, using the Computational Fluid Dynamic "Non isothermal flow" (combining fluid flow and heat transfer, with Boussinesq approximations hypothesis for natural convection analysis), solving a simplified version of eqn (1).

Our future purpose is to determine in detail the air quality and the indoor microclimate, through measurements and implementing $\mathrm{CO}_{2}$ and moisture transport equations in CFD model.

\section{CONCLUSIONS AND PERSPECTIVES}

In industrialized countries, enclosed spaces expose occupants to a wide range of pollutants, and this is aggravated by the fact that people are stationed indoors for about $90 \%$ of their time.

Internal emission sources and formation processes include degassing of building materials, furniture, carpets and fabrics, plants, pesticides, pets, internal physical activities, such as cleaning or vacuum cleaners, heating and cooking, smoke, chemicals and cleaning and personal care residues, certain metabolic processes and indoor air chemistry.

External pollutants can penetrate through the ventilation systems and the building envelope.

The importance of monitoring biotic and abiotic air pollutants indoor is well recognized, and the preliminary results reported in this study are in agreement with previous studies.

The novelty of this work relies in the multidisciplinary approach of the SoS cluster, spanning from physical chemistry to biology to mathematical modelling. To the best of our knowledge, studies carried out with this level of diversity among expertise are rarely found in the literature. With the preliminary results discussed above, we have in fact paved the way to more integrated analyses and to the development of advanced predictive mathematical models. 
In the future, we will validate predictive models taking into account risk factors for human health and indoor aerosol diffusion, with the aim to define usage profiles for healthier and safer buildings. The output will consist in determining in detail the air quality and the indoor microclimate, through measurements, and implementing $\mathrm{CO}_{2}$ and moisture transport equations in the CFD model, potentially linkable with microbial growth.

Considering the qualitative aspect of the analysed parameters, for which it is impossible to use the economic-monetary aspect, a multi-criteria approach is ongoing, and it will be used to assess the impacts for which it is more difficult to attribute an economic value, such as health and IEQ.

The multicriteria analysis will compare the choices made in hypothesized usage profiles, with a mix of characteristics and a mix of more or less satisfactory descriptors.

\section{ACKNOWLEDGEMENTS}

Special thanks to all those who participated in the research "SoS - Sustainability of Schools. Definizione di tecnologie, metodologie e protocolli d'uso per salubrità, benessere e risparmio energetico nei luoghi di formazione" ("SoS - Sustainability of Schools. Definition of technologies, methodologies and protocols of use for health, well-being and energy saving in educational buildings"), that is an interdisciplinary project funded by Roma Tre University, which involves the Departments of Architecture, Economics, Engineering, Mathematics and Physics, and Sciences. This research is published in Extraordinary research development plan, Action 4, for experimental funding action for innovative and interdisciplinary research projects. It is funded with 80,000 euros.

This work is also supported by the Italian Ministry for University and Research (Futuro in Ricerca n. RBFR10LHD1_002 to GR) and by The Grant of Excellence Departments, MIUR-Italy (ARTICOLO 1, COMMI 314 - 337 LEGGE 232/2016) to the Dept. of Science of Roma Tre University.

\section{REFERENCES}

[1] WHO - World Health Organization, Combined or multiple exposure to health stressors in indoor built environments - An evidence-based review prepared for the WHO training workshop "Multiple environmental exposures and risks", 16-18 October 2013 Bonn, Germany. www.euro.who.int/_data/assets/pdf_file/0020/248600/Combinedor-multiple-exposure-to-health-stressors-in-indoor-built-environments.pdf. Accessed on: 25 Apr. 2020.

[2] Lin, Z., Chow, T., Fong, K., Tsang, C. \& Wang, Q., Comparison of performances of displacement and mixing ventilations. Part II: indoor air quality. International Journal of Refrigeration, 28(2), pp. 288-305, 2005.

[3] ANSI/ASHRAE Standard-55-2004, Thermal Environmental Conditions for Human Occupancy, American Society of Heating, Refrigerating and Air-Conditioning Engineers: Atlanta, 2004.

[4] Dimitroulopoulou, C., Ventilation in European dwellings: A review. Building and Environment, 47, pp. 109-125, 2012.

[5] Bulińska, A., Popiołek, Z. \& Buliński, Z., Experimentally validated CFD analysis on sampling region determination of average indoor carbon dioxide concentration in occupied space. Building and Environment, 72, pp. 319-331, 2014.

[6] Daisey, J.M., Angell, W.J. \& Apte, M.G., Indoor air quality, ventilation and health symptoms in schools: an analysis of existing information. Indoor Air, 13(1), pp. 5364, 2003. 
[7] Bakó-Biró, Zs., Clements-Croome, D.J., Kochhar, N., Awbi, H.B. \& Williams, M.J., Ventilation rates in schools and pupils' performance, Building and Environment, 48, pp. 215-223, 2012. https://doi.org/10.1016/j.buildenv.2011.08.018.

[8] Kristensen, M.H., Jensen, J.S. \& Heiselberg, P.K., Field study evaluation of diffuse ceiling ventilation in classroom during real operating conditions. Energy and Buildings, 138, pp. 26-34, 2017.

[9] Song, J. \& Meng, X., The improvement of ventilation design in school buildings using CFD simulation. Procedia Engineering, 121, pp. 1475-1481, 2015.

[10] Hong, T., Lee, M. \& Kim, J., Analysis of energy consumption and indoor temperature distributions in educational facility based on CFD-BES model. Energy Procedia, 105, pp. 3705-3710, 2017.

[11] Mateus, N.M., Simões, G.N., Lúcio, C. \& Carrilho da Graça, G., Comparison of measured and simulated performance of natural displacement ventilation systems for classrooms. Energy and Buildings, 133, pp. 185-196, 2016.

[12] Salerno, G., Teresi, L., Tonelli, C. \& Vitale, V., Numerical modelling of structural cooling in Mediterranean climate. International Journal of Ventilation, 15(3-4), pp. 302-319, 2016.

[13] Gil-Baez, M., Barrios-Padura, Á., Molina-Huelva, M. \& Chacartegui, R., Natural ventilation systems in 21 st-century for near zero energy school buildings. Energy, 137, pp. 1186-1200, 2017.

[14] Vitale, V. \& Salerno, G., A numerical prediction of the passive cooling effects on thermal comfort for a historical building in Rome. Energy and Buildings, 157, pp. 1$10,2017$.

[15] Bourdin, D., Mocho, P., Desauziers, V. \& Plaisance, H., Formaldehyde emission behavior of building materials: On-site measurements and modeling approach to predict indoor air pollution. Journal of Hazardous Materials, 280, pp. 164-173, 2014.

[16] Noh, K.-C., Han, C.-W. \& Oh, M.-D., Effect of the airflow rate of a ceiling type airconditioner on ventilation effectiveness in a lecture room. International Journal of Refrigeration, 31(2), pp. 180-188, 2008.

[17] Salma, I., Dosztály, K., Borsós, T., Söveges, B., Weidinger, T., Kristóf, G., Péter, N. \& Kertész, Z., Physical properties, chemical composition, sources, spatial distribution and sinks of indoor aerosol particles in a university lecture hall. Atmospheric Environment, 64, pp. 219-228, 2013.

[18] Wang, F.-Y., Zhao, J., Kuckelkorn, D., Liu, J. \& Liu, J.-L. Zhang, Classroom energy efficiency and air environment with displacement natural ventilation in a passive public school building. Energy and Buildings, 70, pp. 258-270, 2014.

[19] Wang, Y., Zhao, F.-Y., Kuckelkorn, J., Liu, D., Liu, L.-Q. \& Pan, X.-C., Cooling energy efficiency and classroom air environment of a school building operated by the heat recovery air conditioning unit. Energy, 64, pp. 991-1001, 2014.

[20] Wang, Y. Zhao, F.-Y., Kuckelkorn, J., Spliethoff, H. \& Rank, E., School building energy performance and classroom air environment implemented with the heat recovery heat pump and displacement ventilation system. Applied Energy, 114, pp. 58-68, 2014.

[21] Wang, Y., Zhao, F.-Y., Kuckelkorn, J., Li, X.-H. \& Wang, H.-Q., Indoor air environment and night cooling energy efficiency of a southern German passive public school building operated by the heat recovery air conditioning unit. Energy and Buildings, 81, pp. 9-17, 2014. 
[22] Yu, S., Zhang, G., Ma, Y., Yu Z. \& Feng, G., Numerical simulation study on concentration distribution of indoor pollutions by different natural ventilation strategies in Shenyang. Procedia Engineering, 205, pp. 1389-1396, 2017.

[23] Sarkar, A. \& Bardhan, R., Improved indoor environment through optimised ventilator and furniture positioning: A case of slum rehabilitation housing, Mumbai, India. Frontiers of Architectural Research, 2020.

[24] Guidelines for Indoor Air Quality, Dampness and Mold; World Health Organization, 2009. www.who.int/indoorair/publications/7989289041683/en/. Accessed on: 25 Apr. 2020.

[25] Tahsildoost, M. \& Zomorodian Z.S., Indoor environment quality assessment in classrooms: An integrated approach. Journal of Building Physics, 42(3), pp. 336-362, 2018.

[26] Synnefa, A. et al., An experimental investigation of the indoor air quality in fifteen school buildings in Athens. International Journal of Ventilation, 2(3), pp. 185-201, 2003.

[27] Almeida, R.M.S.F. \& de Freitas, V.P., Indoor environmental quality of classrooms in Southern European climate. Energy and Buildings, 81, pp. 127-140, 2014.

[28] Stabile, L., Dell'Isola, M., Russi, A., Massimo, A. \& Buonanno, G., The effect of natural ventilation strategy on indoor air quality in schools. Science of The Total Environment, 595, pp. 894-902, 2017.

[29] Barbosa, F.C., de Freitas, V.P. \& Almeida, M., School building experimental characterization in Mediterranean climate regarding comfort, indoor air quality and energy consumption. Energy \& Buildings, 212, pp. 109-782, 2020.

[30] Santamourisa, M., Synnefa, A., Assimakopoulos, M., Livada, I., Pavlou, K., Papaglastra, M., Gaitani, N., Kolokotsa, D. \& Assimakopoulos V., Experimental investigation of the air flow and indoor carbon dioxide concentration in classrooms with intermittent natural ventilation. Energy and Buildings, 40, pp. 1833-1843, 2008.

[31] Guidelines for healthy environments within European schools, Publications Office of the European Union, 2014, JRC87071, ISBN: 978-92-79-39151-4, versione italiana, Guidelines on hygiene measures in schools, including recommendations on building construction and maintenance, G.U. 252, 2010. http://sinphonie.rec.org/sites/default/ files/Guidelines/II_Italian\%20Guidelines.pdf. Accessed on: 25 Apr. 2020.

[32] Dacarro, C., Grignani, E., Lodola, L., Grisoli, P. \& Cottica, D., Proposta di indici microbiologici per la valutazione della qualità dell'aria degli edifici. Giornale Italiano di Medicina del Lavoro ed Ergonomia, 22(3), pp. 229-235, 2000.

[33] Grisoli, P., Albertoni, M. \& Rodolfi, M., Application of airborne microorganism indexes in offices, gyms, and libraries. Applied Sciences, 9, p. 1101, 2019.

[34] Holland, N., Bolognesi, C., Kirsch-Volders, M., Bonassi, S., Zeiger, E., Knasmueller, S. \& Fenech, M., The micronucleus assay in human buccal cells as a tool for biomonitoring DNA damage: the HUMN project perspective on current status and knowledge gaps. Mutation Research/Reviews in Mutation Research, 659(1-2), pp. 93108, 2008.

[35] Udroiu, I. \& Sgura, A., Quantitative relationships between acentric fragments and micronuclei: New models and implications for curve fitting. International Journal of Radiation Biology, 96(2), pp. 197-205, 2020.

[36] Udroiu, I., Antoccia, A. \& Sgura, A., Long-term genotoxic effects in the hematopoietic system of prenatally X-irradiated mice. International Journal of Radiation Biology, 93(3), pp. 261-269, 2017. 
[37] Meyer, A.V., Tolochko, T.A., Minina, V.I. \& Timofeyeva, A.A., Influence of DNA repair genes polymorphism on the karyology of buccal epithelium cells in humans exposed to radon. Russian Journal of Genetics: Applied Research, 5(2), pp. 132-140, 2015.

[38] Linhares, D.P., Garcia, P.V., Silva, C., Barroso, J., Kazachkova, N., Pereira, R., Lima, M., Camarinho, R., Ferreira, T. \& dos Santos Rodrigues, A., DNA damage in oral epithelial cells of individuals chronically exposed to indoor radon (222 Rn) in a hydrothermal area. Environmental Geochemistry and Health. 40(5), pp. 1713-1724, 2018.

[39] Balocco, C., Petrone, G., Cammarata, G., Vitali, P., Albertini R. \& Pasquarella, C., Indoor air quality in a real operating theatre under effective use conditions. Journal of Biomedical Science and Engineering, 7, pp. 866-883, 2014.

[40] Balocco, C., Petrone, G., Maggi, O., Pasquariello, G., Albertini, R. \& Pasquarella, C., Indoor microclimatic study for Cultural Heritage protection and preventive conservation in the Palatina Library. Journal of Cultural Heritage, 22, pp. 956-967, 2016. 